\title{
MOTOR EQUIPMENTS FOR THE RECOVERY OF PETROLEUM
}

\author{
BY W. G. TAYLOR
}

\section{Abstract OF PAPER}

The work of drilling, pumping and cleaning oil wells is very successfully handled by slip-ring induction motors. With the cable-tool method of drilling a special arrangement of controllers and resistance is used to obtain the required fine speed control. Similar motors are used for both this and the hydraulic rotary method.

Pumping and cleaning, which includes 'pulling' the rods and tubing, are in most cases all performed by the same motor which may be a 'Y-Delta' or a two-speed machine, depending upon operating conditions. Both of these motors are double-rated, the low rating being used for pumping and the other for pulling and cleaning. High efficiency is essential on the pumping duty and high torque for the heavy work of pulling and cleaning the well. For both types of motors special control features are used to properly protect the equipment as well as to make it most convenient for the operator. For wells pumped by jackrigs, a portable hoist is employed to pull rods and tubing.

This paper presents data covering the horse power requirements and kilowatt-hour consumption for the various operations in drilling and maintaining producing oil wells.

HE GRADUAL decline in production which is characteristic of all oil fields as well as the great losses sustained with the usual methods of steam operation are the factors which generally furnish an incentive to the producing company to electrify its wells. The economy thus gained often gives the wells a longer lease of life, as it enables them to be pumped at a profit at a lower daily production than would otherwise be possible. In most cases economy is only one of the several advantages of motor drive which are taken into consideration, these including greater reliability, simpler and more accurate speed control, steadier speed, greater safety and lower insurance rates than with other types of motive power. These advantages on any motor application are too well known to warrant more than incidental mention.

The choice between alternating and direct current is generally determined by the available power supply and for this reason 
induction motors are used on nearly all electrically operated wells. Several isolated generating plants are in operation which were installed for the purpose of carrying an oil well motor load and which were designed for alternating current because of the inherent superiority for this service of an induction motor over a direct-current machine. Although the latter may at first appear to be a more advantageous type of motor on account of the speed variation obtainable by field control without material reduction in efficiency, yet when it is taken into consideration that oil well motors must often carry sudden and severe overloads and be frequently reversed at full speed, and are subjected to much abusive handling by unskilled operators, the overload limitations of a direct-current motor prove to be a severe handicap. A more complex control is necessary to protect the motor, and if this is not provided the depreciation of the commutator is rapid on the heavy duty.

There is a large number of varied operations which oil well motors are called upon to perform, and these fall naturally into three groups; drilling, pumping and cleaning. The process of drilling a well includes the operations of handling the drilling tools and the casing with which the hole is lined, and of removing the drillings by bailing or hydraulic flushing. The work of pumping includes such operations as are occasionally necessary to free the pump and valves from sand. The cleaning of a well is a process which varies with the conditions encountered. It is always necessary, however, to pull out the rods and tubing, which is known as 'pulling' the well. The accumulated sand and sediment are then removed by bailing or hydraulic washing, and may first require loosening up with a light 'string' of drilling tools. Swabbing is sometimes done to improve the flow of oil.

The most logical method of applying motors to these operations is to use a different machine for each of the three groups, as this not only involves the least complication in design, but also requires the minimum investment by the oil company, consistent with efficient operation. It has, however, been found more practical in most cases to use one motor for the drilling process and another for all the work involved in pumping, puliling and cleaning the wells.

\section{DRILLING}

The two methods of drilling which are in general use in the United States are the standard or cable-tool method, and the 
hydraulic rotary method. The former employs a walking-beam from the end of which a heavy stem and bit are suspended by a steel wire or manila rope. These churn the hole by the up-and-

$A$-Derrick

$B$ - Crown block

$C$-Band-wheel

$D$-Bull-wheel

$E$-Rope-groove for bull-rope

$F$-Bull-wheel band brake

$G$-Calf-wheel with band brake

$H$-Sprocket for driving calf-wheel

$I$-Sand-reel

$J$-Sand-reel friction pulley

$K$-Walking-beam

$L$ - Headache-post

$M$-Samson post

$N$-Pitman

$O$-Crank

$P$ - Countershaft

$Q$ - Motor

$R$-Calf-wheel clutch

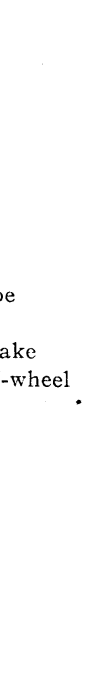


mately 20 -foot lengths, screwed together, but may not be used where there is no danger of caving.

The arrangement of the standard motor-operated drilling rig used in the California fields is illustrated in Fig. 1. For actual drilling work the drilling line is suspended from the end of the walking-beam, but the hoisting of the tools is done by the bullwheel, rope-driven from the band-wheel, with the walking-beam disconnected from the crank. The drilling line is wound on the bull-wheel shaft and passes over a sheave on the crown block. Casing is handled in a similar manner by the calf-wheel, with the addition of a block and tackle having from seven to nine lines. The bailer, which is a long tube with a check valve at the lower end, is hoisted by a separate line wound on the sand-reel, the latter being run from the band-wheel by friction drive. On rigs

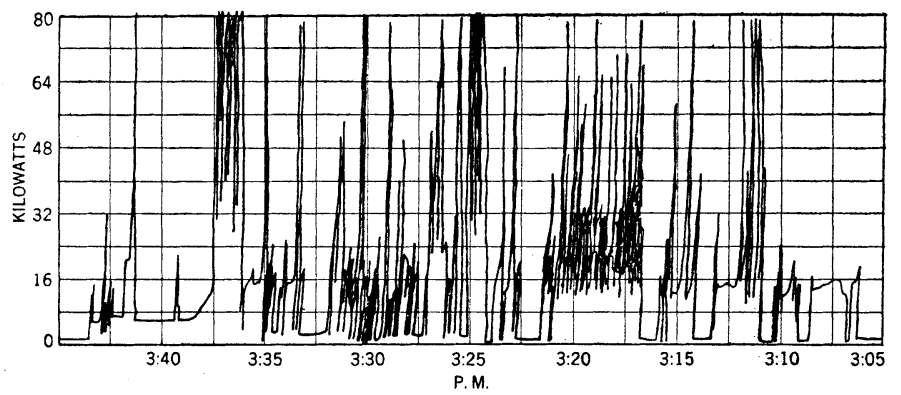

Fig. 2-Graphic Record of Power Required for "Spudding In" Casing in a California Oil Well

not having a sand-reel the bull-wheel is employed for this purpose.

The heaviest work encountered by the drilling motor is the manipulation of the casing. It is frequently necessary to repeatedly raise and lower a string of casing a few feet for long periods in order to relieve the friction caused by pressure of the surrounding strata, and thus work a clear passage. This is known as 'spudding in' the casing. It requires continued reversing of the motor under heavy load, and is very well illustrated by the graphic record shown in Fig. 2, which was made on a 50-h.p. equipment. It is important that the motor should have ample margin in torque to accomplish this without overheating or stalling, as failure to free the string of casing compels the operator to continue with a smaller diameter. Occurrences of this 
kind would result in the minimum diameter being reached at too shallow a depth and thus render it impossible to continue drilling to the oil sand.

The other drilling operations are lighter work for the motor

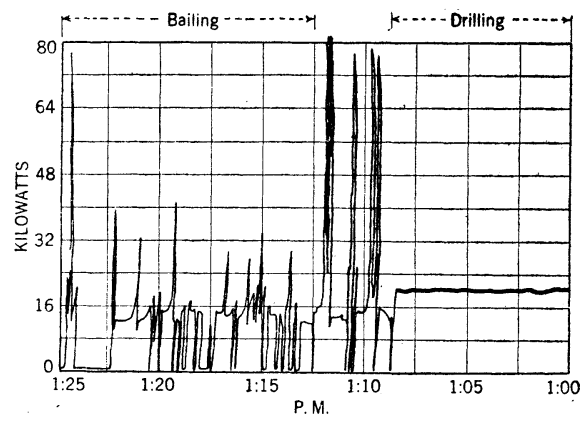

Fig. 3-Graphic Record of Power Required for Drilling and Bailing Work in a California Oil Well

as will be seen by a comparison of Figs. 2 and 3 . The power demand from the motor to merely swing the tools during actual drilling by the cable-tool method is fairly steady, as Fig. 3 shows, but it is interesting to note that this demand becomes less as the well grows deeper. Fig. 4, which represents this

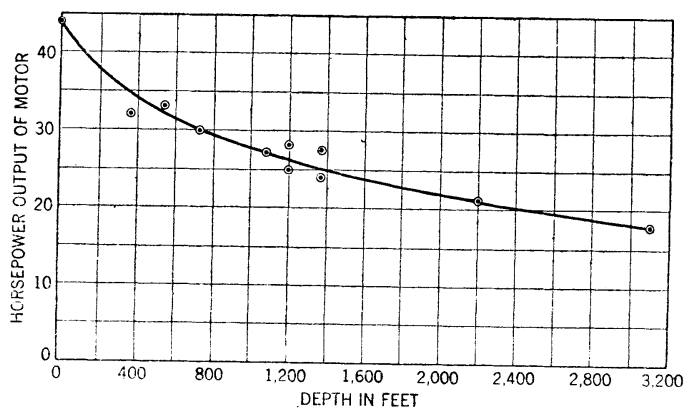

Fig. 4-Horse Power Required for Swinging Standard Cable Tools in Drilling a 3100-Ft. OIL Well in West Virginia

fact, shows a curve plotted from readings taken during the various stages of drilling a $3100-\mathrm{ft}$. well. The point may be explained by the facts that as the well grows deeper the drilling tools used are smaller in diameter and lighter in weight, and a larger amount of water is usually carried in the hole. 
After a well has reached a depth of 300 or $400 \mathrm{ft}$., the amount of energy required per hundred feet for all drilling operations by the standard method increases with the depth of the well. A1though it has already been pointed out that the power necessary to swing the tools grows less, on the other hand the length of time required for bailing increases in proportion to the depth, with little or no reduction in horse power, and the dash-pot action in pulling out the bailer becomes greater due to the larger amount of fluid carried in the well. It is also usually necessary to work the casing more frequently as the depth increases, in order to prevent it from 'freezing' or sticking. Both of these conditions cause a considerable increase in energy consumption. Furthermore, progress becomes slower as the well deepens. Therefore considering all of these points, it is apparent that the $\mathrm{kw}-\mathrm{hr}$. consumption will increase more rapidly than in direct proportion to the depth, and actual results plotted in Fig. 5 for a 2060$\mathrm{ft}$. well indicate that it varies approximately as the square of the depth, barring accidents and extensive jobs of 'fishing' for lost rope, tools or damaged casing. The individual points also plotted in

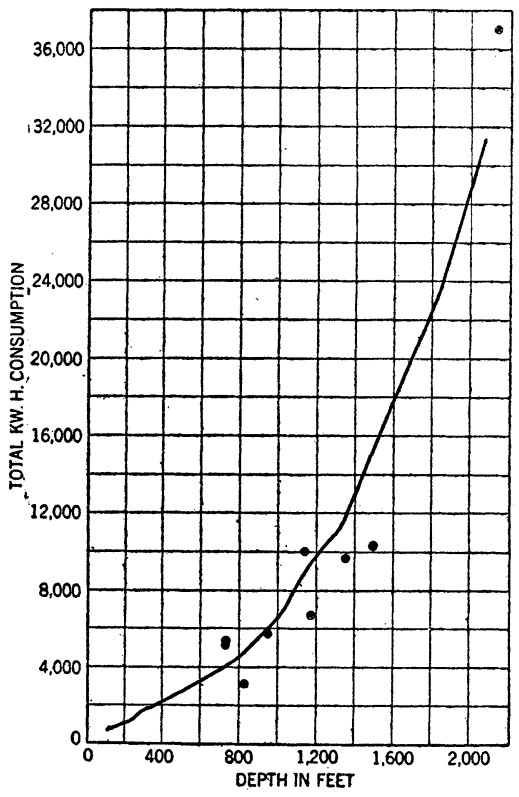

Fig. 5-Curve of Total Power Consumption Covering all OpERATIONS in Drilling a 2060-FT. Oil Well by the Standard CableTool Method. The Individual POINTS PLOTTED ARE THE TOTAL RECORDED KW-HR. ON VARIOUS OTHER Wells

Fig. 5 represent the total power consumption recorded in drilling other wells of various depths. They check as closely as could be expected with the record for the $2060-\mathrm{ft}$. well at a corresponding depth. Under the usual conditions encountered, and without any great amount of bad luck in the drilling work, the average daily power consumption when the motor is in use, is about $230 \mathrm{kw}$-hrs., but it will vary on different days from approximately 135 to $400 \mathrm{kw}-\mathrm{hr}$., depending upon what class of work is being done. 
The most successful drilling motors now used in American oil fields are of the slip-ring induction type with secondary resistance control arranged for reversing duty. A capacity of 50 h.p. is usually sufficient for wells not exceeding 2500 ft. in depth, though cases have occurred where 75 h.p. was necessary on wells from 2000 to $2500 \mathrm{ft}$. in depth, as well as on the deeper ones. The belted arrangement with a countershaft has proved the best, as the severe service has rapidly put out of commission the various types of gear drive which have been tried.

In the cable-tool method of drilling, the beam must overspeed and allow a relatively free drop of the tools on the down stroke to obtain the most effective blow; the motor to accomplish

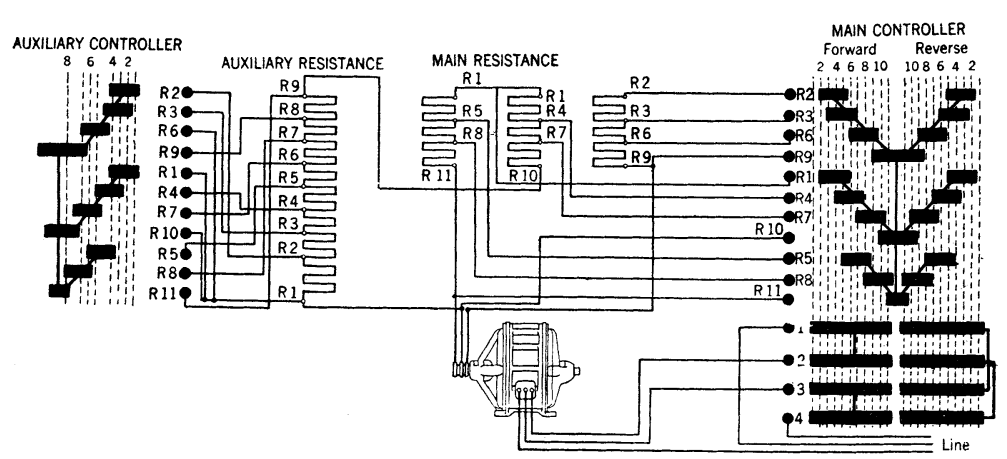

Fig. 6-Connections for Motor Equipment for Standard CableTool Drilling

this must therefore slow down on the up stroke and speed up on the down stroke. This is quite successfully accomplished by so proportioning the pulleys that the motor will have some secondary resistance in circuit when running at the correct drilling speed. There is also required a very fine adjustment of speed to make the movement of the beam accord with the natural period of vibration of the drilling line due to its elasticity. Failure to obtain the exact speed results in deadening the movement of the bit and may strain the line and rig dangerously. A suitably designed liquid rheostat would be an ideal method of control if it received the necessary attention and a good quality of water, but unfortunately neither of these can be given it under the usual conditions in the oil fields and so drum controllers have been adopted, connected as shown in Fig. 6. The main 
controller gives a coarse variation of speed and reverses the motor, and the auxiliary controller provides a means of obtaining fine speed control between the points on the main controller for either direction of rotation. These controllers are each operated by wire ropes extending to the headache-post in the derrick, the arrangement in this respect being similar to the method of throttle control employed with engine-driven rigs. A complete installation is shown in Fig. 7 .

Drilling by the rotary method is accomplished by boring rather than by churning the hole. The drilling bit is supported at the lower end of a column of pipe which is held and rotated by a turntable. The latter is driven through a series of chains and gears. A hoisting drum, which is clutched in when desired, is also provided for handling the drilling stem and casing. The drillings are washed out by a stream of thin mud circulated by the 'slush-pump' down through the rotating column of pipe and up outside of it, thus causing the pipe to turn more easily and preventing caving by plastering the sides of the hole with mud. Only a few wells have so far been drilled by this method with motor drive, but excellent results were obtained with the same type of motor as is used for the cable-tool method. A fairly close speed adjustment is needed to operate the bit at the most effective cutting speed, inasmuch as the latter varies with the nature of the strata encountered.

\section{Pumping, Pulling and Cleaning}

Pumping is accomplished by means of a deep-well pump of the plunger type which is lowered on the end of a string of tubing to a sufficient depth to insure ample submersion. The plunger is operated by jointed iron or wooden rods extending down within the tubing and attached to the end of the walkingbeam or to a pumping-jack operated from a central power-head. The flow of oil through the tubing to the surface is governed by suitable check valves in the barrel and plunger of the pump.

The rods and tubing must be frequently removed to clean out the well or to replace broken or worn parts, and the bull-wheel is then employed except where the use of pumping-jacks makes a portable hoist necessary. Rods are pulled with a single line, but a block and tackle with two or three lines is necessary for the tubing. Both are removed in lengths approximately $60 \mathrm{ft}$. long which usually consist of three $20 \mathrm{ft}$. sections screwed together. Bailing, light redrilling, washing or swabbing may be employed in the process of cleaning. 
PLATE XIV.

A. I. E. E.

VOL. $X X X V, 1916$

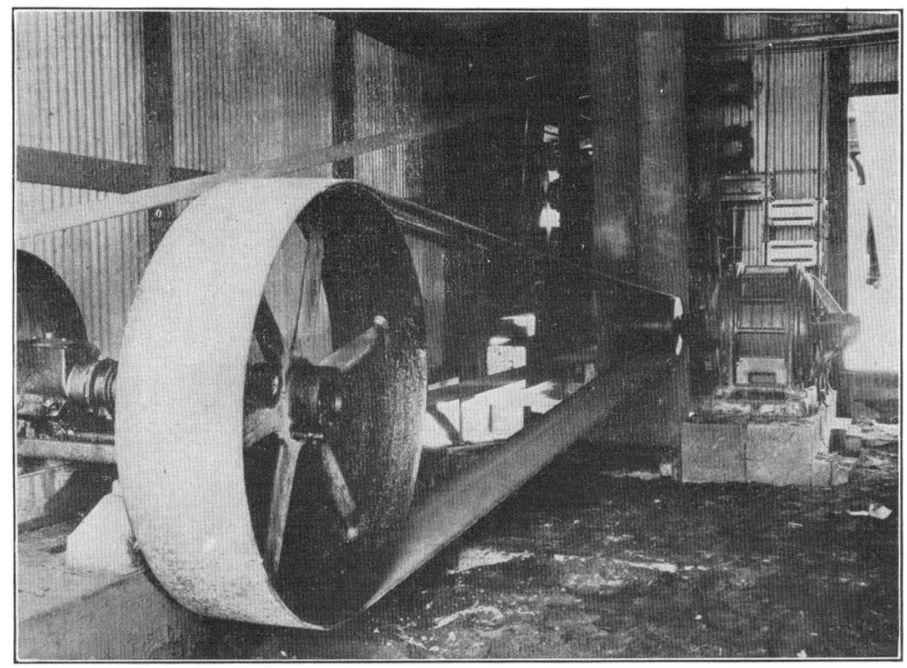

[TAYLOR]

Fig. 7-A 50.h.p. Drilling Motor Operating Cable-Tools on a Standard California Rig

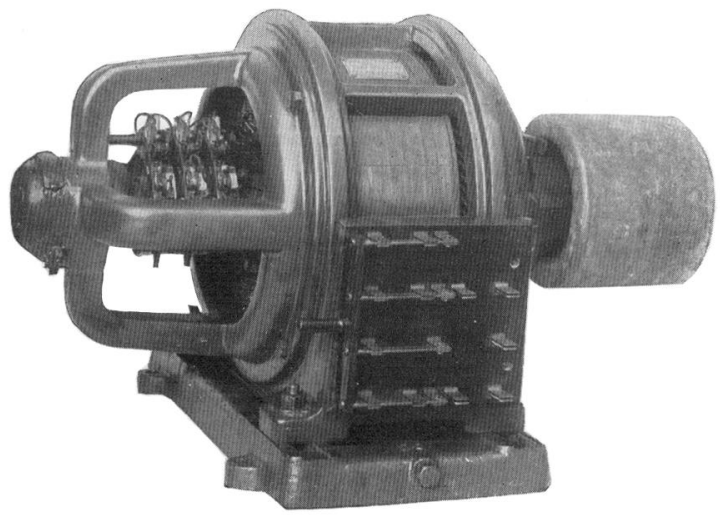

[TAYLOR]

Fig. 9-Two-Speed 25/8-H.P. 1200/600-rev. PER min. Three-Phase, 60-Cycle, 440-Volt Oil Well Motor for Pumping, Pulling and Cleaning Wells of Moderate Depth 
PLATE XV.

A. I. E. E.

VOL. XXXV, 1916

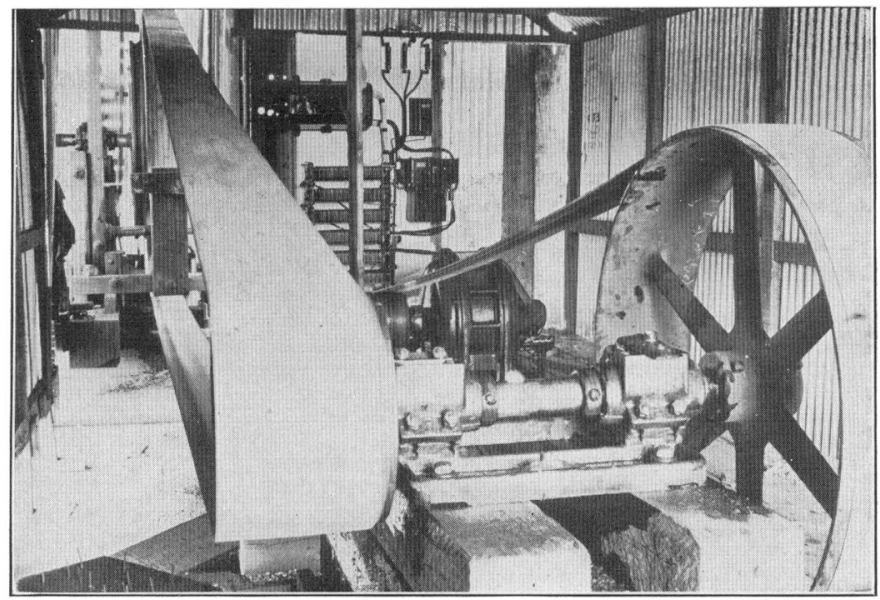

[1 AYLOR]

Fig. 11-Typical Installation of a Two-Speed Belted Motor for Pumping, Pulling and Cleaning Work in the Midway Field in CALifornia

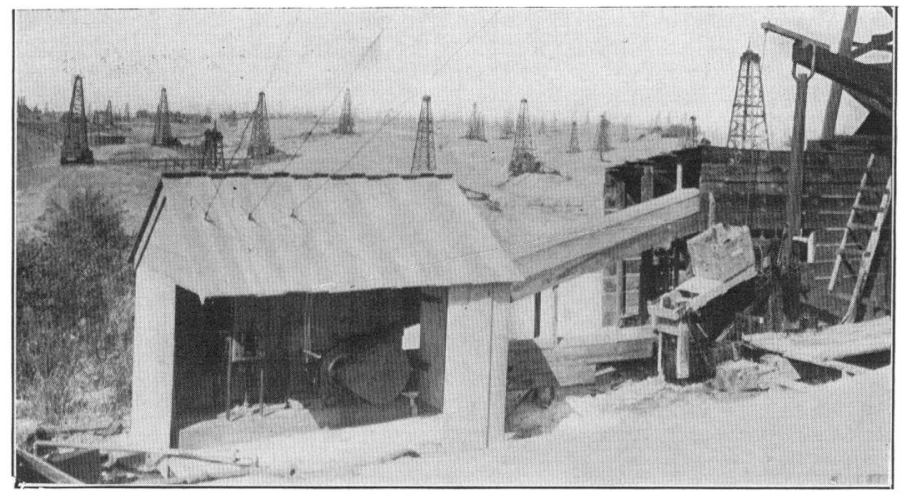

[TAYLOR]

Fig. 12-Back-Geared Oil Well Motor of the Y-Delta Type in the Kern River Oil Field in California

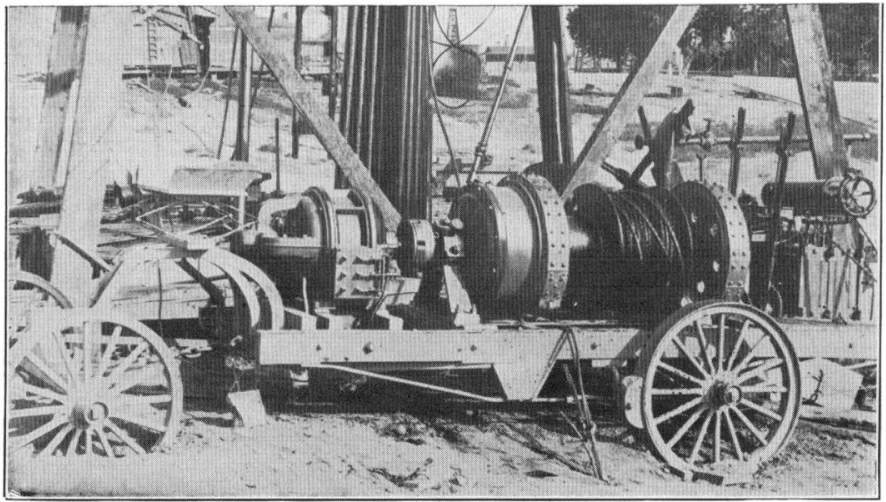

[TAYLOR]

Fig. 13-Portable Electric Hoist Used for Pulling and Bailing Oil Wells Pumped by Pumping Jacks in the Kern River Oil Field in CALIFORNia 
There is no apparent way to calculate the power necessary to pump a well which will give figures uniformly consistent with actual tests, because of the difficulty of determining the effect of varying well conditions. For instance, a large amount of sand in the oil will increase the power necessary to pump it, while on the other hand gas may be present which will help lift the oil. No numerical value can be placed on these conditions, so the motor capacity for this duty is determined largely by comparison with results obtained on other wells. Owing to the fact that the conditions are generally changeable, it is best to have some reserve motor capacity for pumping. The power input will vary from day to day and even from hour to hour, and may increase considerably in a short time when the well is sanding up. Such variations are not so common, however, where the troubles from sand are few.

The following summary of records from over 200 California oil wells pumped on the beam, gives an idea of the motor load for pumping alone:

Depth of wells............ 900 to $3100 \mathrm{ft}$, average $1430 \mathrm{ft}$.

Length of stroke............29 to 32 inches.

Strokes per $\min \ldots \ldots \ldots \ldots \ldots \ldots 20$ to 30 , average 24 .

Diameter of tubing............ 3 inches.

Power required.............

Exceptional wells in California have required as high as 16 to 17 h.p. at times. In Louisiana some heavy pumping wells have been encountered, one in the Evangeline field requiring the following:

Depth of pumping.................... $1100 \mathrm{ft}$.

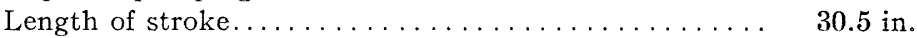

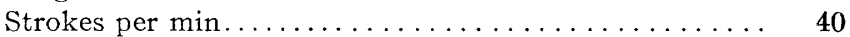

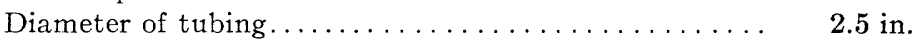

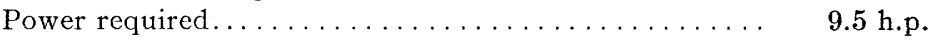

Another Louisiana well near the Caddo field gave test results as follows:

Depth of pumping................... $1000 \mathrm{ft}$.

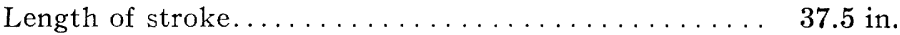

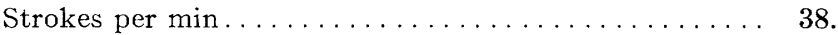

Diameter of tubing................. 3 in.

Power required..........

Compared with the California wells, these Louisiana wells have a longer stroke, higher speed, larger percentage of water and less gas in the oil, and therefore require more power. The 
Caddo well, compared with the one in the Evangeline field, has a little lower speed, but larger tubing and less gas in the oil, and therefore takes more power. The depth of well does not usually appear to be a factor from which any logical conclusions can be drawn.

It is interesting to note that the counterweight which is now quite widely used on the walking-beam to counterbalance the weight of the rods in the well was originally installed to reduce the motor load fluctuation on each stroke, and was found to effect a saving in power as high as 22 per cent in some instances. Its use has since been extended in many cases to engine-driven rigs.

Where changes are frequently taking place in well conditions such as the rate of oil flow, the amount of sand with it, the amount of gas or water in the oil, the viscosity of the fluid or the condition of the pump itself, it is necessary to have a variable-speed motor to permit the operator to pump at what he considers is the maximum economical rate, which may be limited by the rate of oil flow or the rapidity with which the rods and plunger will drop in the oil on the down stroke. On the other hand there are many cases where squirrel-cage motors meet all the requirements of pumping.

Pulling the rods and tubing is ordinary hoisting work, carried on at a maximum speed of the band-wheel which may be from 50 per cent to 100 per cent higher than the pumping speed. It demands an intermittent motor output of from 35 to 80 h.p. or even higher under some circumstances. A high torque machine is therefore most suitable. The greatest heating of the motor occurs when handling rods, because of the very frequent reversals which may occur from three to five times a minute for an hour and a half to two hours at a time. Low armature inertia is consequently very desirable. Pulling tubing requires the highest torque and determines the size of motor necessary. The rating usually given the motor for this duty is merely nominal, as the maximum torque obtainable is the determining feature. The maximum load is that encountered when lifting together the rods and pump and the tubing full of oil. In determining the motor capacity it is convenient to use the following formula for the horse power required to lift tubing at a uniform rate of speed:

$$
\text { h.p. }=\frac{W \times d \times N}{63,000 \times L}
$$


in which $W=$ weight lifted in lbs.

$d=$ diameter of bull-wheel shaft in inches.

$N=$ rev. per min. of bull-wheel.

$L=$ number of lines used in the tackle.

The constant 63,000 is based on a mechanical efficiency of the rig of 50 per cent. This is a fair assumption for the majority of cases, as will be seen by reference to Fig. 8, which is an approximate efficiency curve plotted from the results of several tests. In addition to the value obtained from this formula there must remain a sufficient margin in torque for acceleration. This depends largely upon the flywheel effect of the motor armature, as the revolving parts of the rig have relatively small inertia.

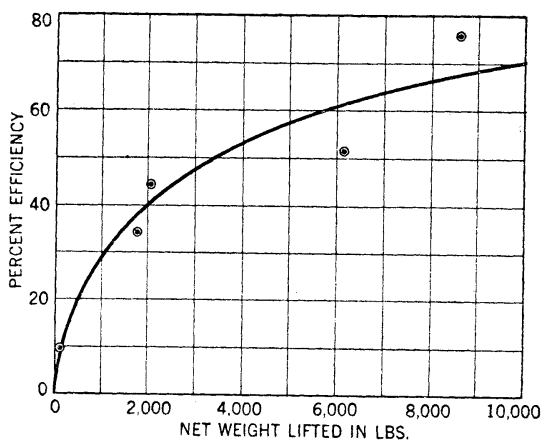

Fig. 8-Approximate Mechanical Efficiency of Standard American Oil Well Rig

Of the various operations of cleaning a well, swabbing requires the heaviest demand of power. The work consists of lowering a plunger into the well casing and then pulling it out. The plunger has a tight fit in the casing so that the suction thus produced draws the sand out of the perforations at the bottom and thus clears the oil passages. The operation may be performed for several hours at the rate of two to four times per hour, each hoisting trip of the swab requiring several minutes. Peak inputs to the motor from 40 to nearly $70 \mathrm{kw}$. have been recorded in this work.

The total monthly power consumption for all the work of pumping, pulling and cleaning a well will vary from approximately 1350 to $6000 \mathrm{kw}-\mathrm{hr}$. but the average is about 2100 $\mathrm{kw}-\mathrm{hr}$. 
The necessity of employing a single motor for all of the work of pumping, pulling and cleaning is due chiefly to two reasons; first, the impracticability of using a portable hoisting equipment for wells that may have to be pulled every few days, particularly where the country is rough; second, the desire of a great majority of operators to have a machine which will take the place of the steam engine with little or no change in the method of operation.

The most successful and most widely used induction motors for this duty are of two types, the 'Y-delta' and the two-speed. Except in special instances both are of the slip-ring type, the former being designed for changing the normal capacity by a change in stator connections made by a suitable switch, this not, however, affecting the speed; the latter has a pole-changing switch mounted on the frame by means of which both the speed and capacity are changed. Both machines require a controller and secondary resistance for speed variation, which with the two-speed motor are effective on either the high or the low-speed connection, as a six-phase rotor winding is used. A synchronous speed of 900 or $1200 \mathrm{rev}$. per min. is usually selected for either type of motor, and a half-speed connection is used on the twospeed machine. Various ratings are employed, depending upon what the conditions require, among which are $20 / 7$ h.p., $20 / 10$ h.p., $25 / 8$ h.p. and $30 / 15$ h.p. Smaller motors than these generally cannot develop the overload torque occasionally necessary in emergencies on nearly all wells. The low capacity is used for little else but pumping, and the design is therefore made for as high an efficiency as possible on this connection without sacrificing the required torque on the higher rating. The maximum momentary capacity is from 300 per cent to 450 per cent of the high rating, but full-load efficiencies of from 75 per cent to 85 per cent, and power factors nearly as good, are nevertheless obtained at full load on pumping duty.

With the Y-delta motor, a high speed for pulling can be obtained only by changing the pulley or by lagging up the bullwheel shaft to a large diameter. Few operators care to be bothered with the pulleys, while there are some who will not consider the other method because of the increased strain on parts of the rig. Lagging the bull-wheel shaft furthermore does not speed up the sand-reel, so bailing must be done very slowly. But where the operator will use a lagged shaft and has no sand-reel, the Y-delta motor does very well, except for one point which 
in many cases is important. It is very often the practise to 'shake-up' a well to free the pump valves from sand arid thus avoid pulling the rods and tubing. This is accomplished by increasing the speed of the walking-beam for a few minutes, but there is no practical way to do so with this type of motor, as the time required to change pulleys makes this method out of the question. The two-speed slip-ring motor, as may readily be seen, overcomes all these difficulties and has therefore received wide-spread approval by practical oil men. One of these motors is illustrated in Fig. 9.

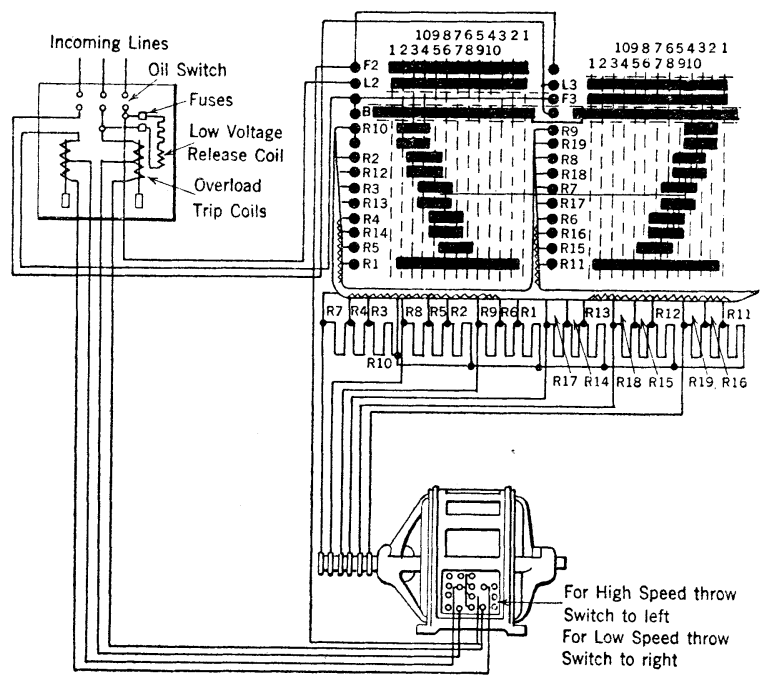

Fig. 10-Connections for Two-Speed Motor Equipment for Pumping, Pulling and Cleaning Duty

The connections of the two-speed equipment in Fig. 10 show. the method of protecting the double-rated motors by doublewound overload trip coils on the oil switch, which are so interlocked by connections with the switch on the motor that proper protection is automatically obtained. The controller is operated by a rope wheel from the derrick as described for the drilling motor.

While the majority of installations use a belted motor with countershaft, there are many back-geared machines in operation, the two arrangements being shown in Figs. 11 and 12. Oil men display a preference for the former, but most of the gear noise 
has been eliminated on the most recent back-geared installations by the use of cloth pinions, and it is anticipated that more of these will be used in the future.

The use of separate motors for pumping and pulling work requires little comment, as it is a simple proposition to select machines with the proper characteristics. The hoist motor must be portable, and either it may be coupled to a hoist mounted on a truck as shown in Fig. 13, or the motor equipment may alone be portable and designed to be belted to the countershaft at each well. Both methods are successfully used. The complete portable hoist is better adapted for wells pumped by pumpingjacks.

Pumping-jacks are operated together from a central point, the reciprocating motion being obtained by eccentrics or cranks which are belt driven. Motors have been applied to a large number, but no features of unusual interest are involved, as the duty is non-reversing and a friction-clutch is frequently used for starting the load. It is an interesting comparison with the individually driven well to note that the power required for jackrig pumping averages approximately 2.5 h.p. per well and the average consumption is from 30 to $45 \mathrm{kw}$-hr. per day. The use of jacks has more than cut the power bill in two in some cases, but they are considered advisable only when the well production falls very low, as their use causes a loss of from 15 per cent to 25 per cent in production because of the impossibility of running each well at its most advantageous speed.

Oil well motors have been used in eastern United States fields for the past twelve years, but active interest was not taken in them in California and the middle west until 1910. The conditions encountered in those fields required the development of the equipments described in this paper, which with little or no change can successfully meet any conditions so far encountered in this country. During the first three years over a thousand wells were electrified in California alone. Although very little development work has taken place in the fields during the past two years due to the very low market price of oil, it is estimated that there are between 1500 and 2000 electrically-operated oil wells in the United States at the present time.

No attempt has been made in this paper to give comparative operating costs, as a considerable amount of valuable data on that subject has already been published and is readily available to those interested. 
Discussion on "Motor Equipments for the Recovery of Petroleum" (Taylor), Cleveland, Ohio, June 27, 1916.

F. Woodbury: About five or six years ago I was associated in the pioneer work near Los Angeles where some of these oil well motors were developed. We had considerable trouble owing to the prejudice of the operators against the apparatus, as mentioned by Mr. Taylor. They endeavored to discredit the motors by running full speed and reversing as fast as they could, doing everything possible to burn them out. However, in this they were not very successful, and we finally succeeded in successfully installing several motors.

The largest saving to be effected by motor operation is with producing wells which require pumping. Wells in process of drilling are comparatively few, so it is questionable if much is to be gained by using motors for this severe duty. An example of what was saved on the property where the development work took place is herewith given. Before electrification all of the natural gas on the property plus 30 to 50 barrels of oil was burned per day to produce the necessary steam for the pumping engines. After equipping 15 or 20 wells with pumping motors it was found no longer necessary to burn any oil, and there was an excess of natural gas. Electric power was supplied from a small plant receiving steam from the same boilers that were used to supply the pumping motors.

Mr. Taylor notes that there are many instances where it is hard to get motors installed due to local conditions not being suitable. This is quite true in cases where there is ample natural gas and the prospective customer is using gas engines. In other cases where crude oil is used for steam generation and the steam is piped considerable distances, large savings can be made by using motors.

A. M. Dudley: There is one fact that Mr. Taylor has not dwelt on, and that is the greater convenience of the electric motor. In such territories as the oil fields of West Virginia the hauling of a heavy steam boiler over the rough country is a serious problem. Six horses and even eight are often employed. You can readily appreciate that a motor occupying possibly 4 or 5 cubic feet and weighing not over 700 or 800 pounds is a most acceptable substitute.

Another point, is the great flexibility of the induction motor in the performance of any and all classes of work. It has been brought to your attention in connection with the paper on reversing rolling mills that in many cases the limiting factor of the d-c. motor is commutation. The induction motor has no commutation and for short-time loads is limited practically only by the maximum torque it will develop. Mr. Taylor also shows that by connecting $\mathrm{Y}$ and $\Delta$, a maximum torque practically three times as great may be developed where needed for short 
periods in cleaning and "pulling." and that this is coupled with high efficiency when pumping continuously for days at a stretch. Another point brought out, is the possibility of connecting the same winding for two speeds and thus further adapting the motor to its work. From many points this is almost an ideal combination of motor and tool characteristics. 